\title{
The Bureau of Communications Research - Q \& A with Dr Paul Paterson
}

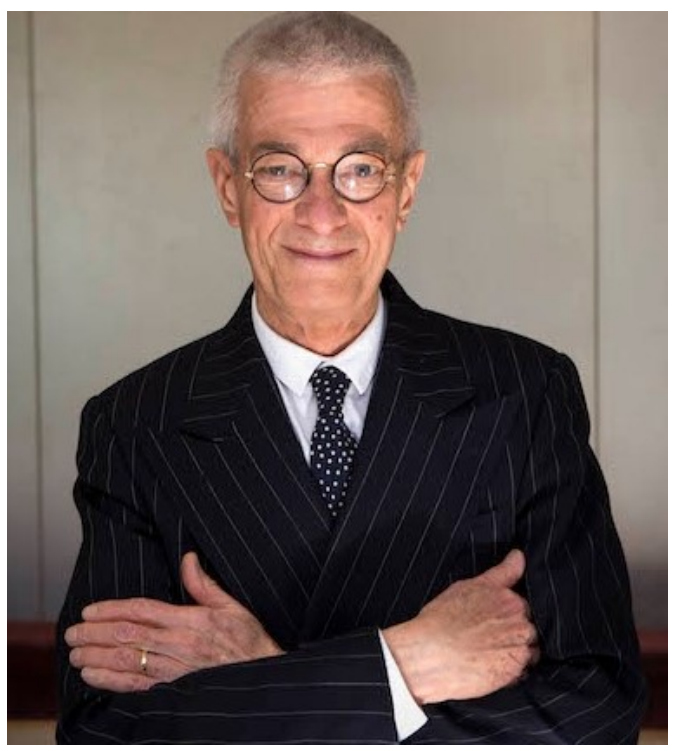

Dr Paul Paterson was recently appointed as Chief Economist of the Commonwealth Department of Communications and Head of the new Australian Bureau of Communications Research. He brings more than 25 years' experience in advisory, regulatory, programme delivery, senior policy and research positions in the private and public sectors both in Australia and overseas to this role. He holds a PhD and Master of Economics from the Australian National University and a Bachelor of Agricultural Economics (First Class Honours), from the University of New England. He has a strong knowledge base in the telecommunications, media and postal sectors and, in particular, advising on issues such as fixed and mobile broadband network investment, access regulation, USO policy, media content rights and telecoms-media convergence.

Dr Paterson is currently finalising his role as a tribunal member of the NSW Government's Independent Pricing and Regulatory Tribunal (IPART). His past roles include a term as an independent advisor on the IT Start-ups Advisory Board and numerous research assignments, and, in his quieter moments, he has run his own consultancy practice.

He recently answered some questions from The Australian Journal of Telecommunications and the Digital Economy (ajTDE) about the Bureau, its work and his view of the future.

ajTDE: What is the purpose of the Bureau of Communications Research (BCR) and how has it been set up?

PP: The Bureau of Communications Research was established within the Commonwealth Department of Communications on 1 September 2014 as a progressive advocate for factbased research and policy in the online world. The launch of the Bureau will help to inform both policy development and public debate and is a key strategic step for the Department in valuing a stronger knowledge base, and an exciting addition to the communication sector. As the Head of the Bureau, and Chief Economist within the Department, I am supported by 20 highly effective staff with a wealth of skills and experience in working across the telecommunications, media, post and IT-based applications sectors. 
Specifically, the Bureau:

- has been established to publish authoritative, easy-to-digest research and analysis to inform policy development

- will support the Department's role as the advisor on communications policy

- has established work stream priorities in economics, market analysis, data and statistics, and economics communication, and

- will build its reputation for providing robust, independent, expert economic and technological research.

ajTDE: What attracted you to this role, and what experience do you bring to the BCR?

$\boldsymbol{P P}$ : Along with a $\mathrm{PhD}$ in Economics and extensive experience in senior policy and research management positions in both the public and private sectors, I have a strong knowledge base in the telecommunications, media, post and IT-based applications sectors. My past experience also includes advising on issues such as fixed and mobile broadband, network investment, access regulation, USO policy, media content rights and telecoms-media convergence.

This role offers a unique opportunity to share that knowledge and experience and join a Department which is dedicated to the advancement of an innovative and competitive communication sector through fact-based policy advice to the government.

ajTDE: What plans do you have for the BCR over the coming year?

$\boldsymbol{P P}$ : This initial establishment phase involves me, as Head of the Bureau, engaging with stakeholders across government, industry and the research community to understand their issues and priorities and opportunities for partnering. While staff are already working on a number of important internal projects with the policy areas across the Department, I am developing the overarching framework and rationale for our research program and agenda to guide the forward work program of the Bureau.

I expect that the work of the Bureau will be a mix of shorter-term projects that are built around a program of longer term research initiatives. Projects will be relevant to the issues and priorities identified, and will be undertaken in consultation with the Department's policy areas, the Minister and wider stakeholders. The Bureau will be publishing some material externally, while other work will feed into initiatives already underway within the Department. 
ajTDE: What are your preliminary ideas on the key issues the BCR might address in its first 12 months and longer term?

PP: The communications, digital technology, media and post sector is central to our overall economic competitiveness and productivity. The sector is future-focused and intrinsic to the performance of other sectors across the economy from agriculture to financial services.

Within the sector we are familiar with the digital revolution but we need to do more work to set out how this is shaping our economy, undertake research to ensure that this is as productive and economically efficient as possible and identify the barriers to future growth and competition. I am expecting that the Bureau's research program in its first year will be working across the following layers of investigation:

- Understanding the fundamental role of ICT in economy-wide productivity growth-that warrants the same intense level of attention/priority as financial and labour market reform

- Cataloguing the likely sources of inefficiency in ICT markets-recognising that these are likely to be different to those traditionally addressed due to ICT convergence and the deep interconnectedness of the ICT sector with all economic (and social) activity

- Identifying the top-priorities for reform in telecoms, media, post, computing and applications markets-to enable these markets to operate as efficiently as possible

- Establishing and pursuing the BCR's research, market analysis and database programfor the immediate and longer term.

Along the way the activities we are planning include leading indicators, comparative policy studies, market design issues and snapshots into new data and research that will put the Bureau on the map, so-to-speak.

ajTDE: As Chief Economist and Head of the Bureau, what do you see will be the main challenges to delivering in this area?

$\boldsymbol{P P}$ : I am conscious that as a 'digital born' research team, we are well placed to see such things as the growth of big data and the Internet of Things in a larger field which is always seeking to be at the forefront of innovation. A key challenge for the Bureau, as a small team, is to balance the competing priorities, focus on adding value and, above all, be relevant and influential. The Bureau is developing strategies to overcome these challenges so we can thereby support the Department's policy leadership role, build stronger stakeholder relationships and stimulate informed discussion on policy and regulatory issues. It's a very exciting time. 